feature of the shoots bearing induced ovate leaves is the development of axillary buds (with ovate leaves) associated with the absence of elongation of the shoot after immersion in the diluted sea water.

These results are being considered in relation to a general study of heterophylly in Callitriche intermedia.

Department of Botany,

University College of Wales,

Aberystwyth. July 22.

${ }^{1} \mathrm{M}$ IcCallum, W. B., Bot. Gaz., 34, 93 (1902).

${ }^{2}$ Burns, G. P., Ann. Bot., 18, 579 (1904).

\section{Lowered Liver Vitamin A Reserves in Avian Coccidiosis}

DURING the course of a routine series of determinations of vitamin A reserves of poultry in health and disease it became evident that, in the case of fowls affected with coccidiosis, these reserves were almost invariably of a low order.

The range in a series of thirty-nine affected birds submitted for diagnosis from farms in different parts of England was 0-126 1.U. vitamin A/gm., with a mean value of $6.9 \mathrm{I} . \mathrm{U} . / \mathrm{gm}$.

The birds in question were of varying ages and breeds and were from farms on which widely different systems of husbandry were practised. The infections included both the cæcal type (Eimeria tenella) and the intestinal type (Eimeria necatrix) of coccidiosis.

Observations were therefore extended to a series of ten Barred Rock and Brown Leghorn $\times$ Barred Rock fowls which were suffering from a natural infection of intestinal coccidiosis, and which were from a flock maintained at the Poultry Research Station of the Animal Health Trust, where they had been reared on range in fold units. The ages of the birds varied from 8 to 24 weeks, but in all cases the liver vitamin A reserves were again of low order, the range being 2-38 I.U./gm. with the mean of 20.8 I.U. $/ \mathrm{gm}$. The food provided was a nutritionally balanced ration and was known to contain $2,100 \mu \mathrm{gm}$. carotene $=3,500$ I.U. vitamin $A / \mathrm{lb}$. in the form of dried grass meal. The livers of ten unaffected birds from the same flock were examined and found to have normal reserves within the range of 200-420 I.U./gm., with a mean value of 292 I.U./gm.

These findings would appear to be of special interest in view of the fact that the intestine is now recognized as the seat of conversion of carotene to vitamin $A$, in chicks as well as mammals'. It is suggested that invasion of the intestinal wall by the coccidia may have resulted in impaired conversion of carotene to vitamin A. Moreover, it has been shown that the provision of adequate amounts of cod liver oil accelerates recovery from coccidiosis ${ }^{2}$, and this may be due to its vitamin $\mathrm{A}$ content.

These studies are now being extended to birds artificially infected with Eimeria necatrix and receiving vitamin $A$ either as the vitamin $A$ alcohol or as carotene.

I am grateful to Dr. Horton-Smith for his collaboration.

Poultry Research Station,

Animal Health Trust,

Houghton, Huntingdon. Oct. 7.

${ }^{1}$ Kon, S. K., and Thompson, S. Y., Brit. J. Nutrii., 5, 114 (1951).

2 Murphy, R. R., Hunter, J. E., and Knandel, H. C., Poult. Sci., 17, 377 (1938).

\section{Spread of Pigment in Sheep Skin Autografts}

Several theories have been advanced to explain the spreading of melanin pigmentation in mammalian skin during post-natal life ${ }^{1}$. Billingham and Medawar ${ }^{2}$ found support for their theory of 'infective' cellular transformation from skin grafting experiments with guinea pigs. It is well known that if black skin from an adult guinea pig is grafted on to a white area on the same animal, melanin pigment appears in the white skin surrounding the graft, though not in the hairs. A similar phenomenon was recently observed with grafts of cattle skin ${ }^{3}$. The spreading of pigment to surrounding hairs instead of to epidermis has been reported in homografts to new-born mice ${ }^{4}$ and in autografts to new-born black hooded rats $^{1}$; but, so far as we are aware, it has not been observed in the healthy skin of more mature mice or rats, nor in any species other than the above.

In the black skin of sheep, pigmented dendritic cells are present in the hair matrix of hair follicles and in varying concentrations in the root sheaths and the basal layer of the epidermis. Boyd ${ }^{5}$ showed that dihydroxyphenylalanine-positive but unpigmented dendritic cells were present in the same locations in the white skin of spotted and recessive white breeds. The distribution of dendritic cells was the same in spotted guinea pigs ${ }^{2}$, although in the latter the unpigmented dendritic cells were negative to dihydroxyphenylalanine.

In the course of skin autografting experiments on sheep, with techniques similar to those used by Billingham and Medawar' for rodents, fitted thin Thiersch grafts were made from a black skin patch on the thigh to the white skin of the thorax of a two-months old merino lamb. The grafts 'took' and the grafted skin produced a normal crop of wool fibres. The black pigmentation of epidermis and hairs persisted in the grafted skin. About fifteen days after the operation, pigment was observed spreading into the surrounding white recipient skin. At first the pigment was confined to the epidermis of the recipient skin, but after twenty-five days it was noted in a few wool fibres, and at forty days very many of the fibres on this marginal area were black. Further tests are required to determine whether the black fibres were derived solely from follicles which developed after pigment had spread to the epidermis. The accompanying photograph shows the shaved surface sixty days after the operation, with three grafts of black skin, each surrounded by a grey ring of recipient skin. In another experiment, grafting of skin from a black patch on the neck to the white skin of the thorax of an 8-months old ewe caused

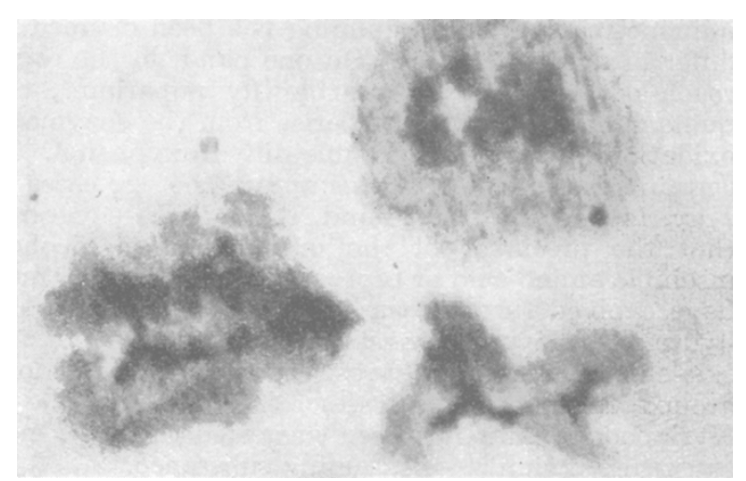

